\title{
Best Row Number Ratio Study of Surface Air Coolers for Segmented Handling Air-conditioning System
}

\author{
Pengjie Fan ${ }^{1, a}$, Caihua Liang ${ }^{1, b}$ and Xiaosong Zhang ${ }^{1, c}$ \\ ${ }^{1}$ School of Energy and Environment, Southeast University, Nanjing 210096, China \\ afanpjseu@qq.com, ${ }^{b}$ caihualiang@163.com, ${ }^{c}$ rachpe@seu.edu.cn
}

Keywords: high/low temperature surface air cooler, thermal-moisture segmented handling, variable row number ratio, and energy-saving rate

Abstract. The row number ratio between high temperature surface air cooler and low temperature one of segmented handling air-conditioning system has great impact on its performance. To study the variation of the system performance on different row number ratios, a performance prediction model of the segmented handling process is developed, and an experimental device including high/low temperature surface air coolers and high/low temperature water chillers is built up, analysis of the simulation and experiment of segmented handling air-conditioning system on three different row number ratios $(2: 2,1: 3,3: 1)$ under variable supply temperature of high temperature chilled water is studied. The results show that relative errors of performance parameters such as total heat exchange, energy-saving rate and dehumidification quantity between simulation and experiment are within 12\%; The adjustable range of total heat exchange and dehumidification quantity of the system caused by chilled water temperature increasing from 7 to $19^{\circ} \mathrm{C}$ on $3: 1$ is bigger than on $2: 2$ and on 1:3 , and the energy-saving rate of the system on $3: 1$ is the most when the inlet air dry-bulb temperature is $26^{\circ} \mathrm{C}$; The energy-saving rate on 2:2 is equivalent to on 3:1 and the dehumidification ability on 2:2 is better than 3:1 when the part load of system is larger.

\section{Introduction}

With the rapid economic development and improvement of human living standards, the proportion of air-conditioning energy consumption in building energy consumption also increases rapidly. Statistics show that air-conditioning system runs off with 50\% 70\% of building energy consumption in summer. At present, the design of conventional air-conditioning system is based on the full load of the building, however, air-conditioning system operates in part load less than $60 \%$ for more than $80 \%$ of its running time [1]. Therefore, studying air-conditioning system's operation laws in part load and obtaining optimal control strategy are quite significant for the system designed for operating best at rated condition to achieve high efficiency and energy-saving operation under all conditions.

Central air-conditioning system is mainly composed of water chiller, conveying cooling equipment and air handling unit (AHU). The water chiller is the main energy consuming part of air-conditioning system, many scholars start with the system to achieve energy-saving of water chiller by using simulation models and control strategies [2-4]. Efficient central air-conditioning system also needs a higher efficient conveying system, in addition to the high efficiency of water chiller, which means the configuration and operation of water chiller, water pump and fan should be reasonable[5, 6]. In recent years, the energy-saving of AHU have been concerned and studied by more and more scholars [7, 8]; Surface air cooler, as the main component of AHU, plays a decisive role in the heat and mass transfer efficiency between chilled water and air. Mei et al. [9] established a mathematical model of surface air cooler, and proposed a control strategy regulating both chilled water flow and air volume of surface air cooler aimed at the air-conditioning system in part load. Lee [10] discussed the heat and mass transfer calculation of surface air cooler in wet-dry cooling condition, and presented a simplified model to avoid the iterative operation. Considering the shortcomings of the existing air handling method, Liang et al. [11] proposed an air thermal-moisture segmented handling method which used high/low temperature surface air coolers replace the only one surface air cooler of conventional AHU, so as to avoid the irreversible loss caused by using low temperature chilled water to bear sensible heat load. Considering 
the economy of air-conditioning system (compared with the conventional AHU, the total heat exchange area of surface air cooler remains constant), the heat exchange area ratio (row number ratio) of high/low temperature surface air coolers has a great influence on the energy-saving effect of the segmented handling air-conditioning system, however, related research has received less attention so far.

To this end, a simulated model and an experimental device including high/low temperature surface air coolers and high/low temperature water chillers are built up based on the air thermal-moisture segmented handling system which is composed of high/low temperature surface air coolers, analysis of simulation and experiment of the segmented handling air-conditioning system on three different row number ratios $(2: 2,1: 3,3: 1)$ under variable supply temperature of high temperature chilled water is studied to provide guidance for the optimal design of row number ratio and the optimal operation of the segmented handling air-conditioning system when the system load change.

\section{Principle of air thermal-moisture segmented handling and its performance model}

Thermal-moisture segmented handling principle. Air-conditioning load include latent heat load and sensible heat load, in the conventional air-conditioning system, the latent heat load and sensible heat load of air is treated simultaneously by the only one surface air cooler in AHU: air is cooled down and dehumidified in the only one cooler to achieve the required state, as shown in Fig. 1, the mixed air (M) of return air $(\mathrm{H})$ with fresh air $(\mathrm{X})$ is handled directly into its supply state $(\mathrm{S})$, that is M-S process. In order to remove the latent heat load of air, chilled water temperature supplied by water chiller must be low (the normal is $7^{\circ} \mathrm{C}$ ), however, handling the sensible heat load (larger proportion of total heat load) could use a higher temperature chilled water considering from the energy-saving viewpoint [12]. So the air thermal-moisture segmented handling method was put forward, Its basic principle is using two surface air coolers (high/low temperature surface air coolers) replace the only one surface air cooler in conventional AHU: high temperature surface air cooler mainly bears sensible heat load (M-Z) by supplying high temperature chilled water, low temperature surface air cooler mainly bears latent heat load (Z-S) by supplying low temperature chilled water $\left(7^{\circ} \mathrm{C}\right)$.

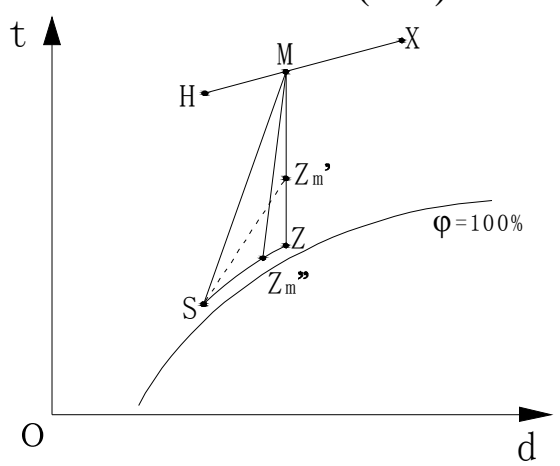

Fig.1 Schematic of air thermal-moisture segmented handling principle.

The segmented handling air-conditioning system includes two water chillers which supply high/low temperature surface air coolers with high/low temperature chilled water respectively to reduce the irreversible loss of system. The energy-saving effect of system can be evaluated with energy-saving rate [11]:

$$
S=s\left(t_{1}-t_{2}\right) \cdot q_{1} /\left(q_{1}+q_{2}\right)
$$

In the above equation, $s$ is the percentage increased in COP when chilled water temperature increase of $1{ }^{\circ} \mathrm{C} ; t_{1}$ and $t_{2}$ are the supply temperature of high/low temperature chilled water respectively; $q_{1}$ and $q_{2}$ are the heat exchange of high/low temperature surface air cooler.

From Fig. 1, we can find that the intermediate state $(\mathrm{Z})$ of air can be $\mathrm{Z}_{\mathrm{m}}$ ' or $\mathrm{Z}_{\mathrm{m}}$ ", which is decided by the heat exchange area ratio of high/low temperature surface air coolers and the supply temperature of high temperature chilled water, affecting final supply state of air and energy-saving effect of system. So it is necessary to study the performance variation of the system on different row number ratios when the supply temperature of high temperature chilled water changes. 
Simulation model of thermal-moisture segmented handling system. Cooling module in AHU of the segmented handling air-conditioning system consists of high/low temperature surface air coolers. The air thermal-moisture segmented handling system simulation model can be build up by coupling high temperature surface air cooler mathematical model with low temperature surface air cooler mathematical model.

The interaction of air in the high/low temperature surface air cooler is consistent with the interaction in the conventional surface air cooler, so the high/low temperature surface air cooler mathematical models can be established in the same way as the conventional one. Make the following assumptions for establishing surface air cooler mathematical model: (1) ignore the heat exchange with environment; (2) the average percentage increased in COP when chilled water temperature increase of $1{ }^{\circ} \mathrm{C}$ is $3 \%$, namely $s=3 \%[13]$.

$$
Q=m_{\mathrm{a}}\left(h_{1}-h_{2}\right)=m_{\mathrm{w}} c_{p}\left(t_{\mathrm{w} 2}-t_{\mathrm{w} 1}\right)
$$

Where $Q$ is the heat exchange of surface air cooler; $m_{\mathrm{a}}$ and $m_{\mathrm{w}}$ are flow of air and chilled water, $h_{1}$ and $h_{2}$ are inlet/outlet air enthalpy; $c_{p}$ is the specific heat of chilled water; $t_{\mathrm{w} 1}$ and $t_{\mathrm{w} 2}$ are inlet/outlet chilled water temperature.

Use the Sieder-Tate correlation to calculate water-side convective heat transfer coefficient $\left(\alpha_{\mathrm{i}}\right)$ in the tube:

$$
a_{\mathrm{i}}=1.86\left(\operatorname{Re}_{\mathrm{f}} \operatorname{Pr}_{\mathrm{f}} \frac{d_{\mathrm{i}}}{l}\right)^{1 / 3}\left(\frac{\eta_{\mathrm{f}}}{\eta_{\mathrm{w}}}\right)^{0.14} \frac{\lambda_{\mathrm{f}}}{d_{\mathrm{i}}}
$$

Where $R e_{\mathrm{f}}$ and $P r_{\mathrm{f}}$ are Reynolds number and Prandtl number of water; $\eta_{\mathrm{f}}$ and $\eta_{\mathrm{w}}$ are kinetic viscosity of water and tube wall; $\lambda_{\mathrm{f}}$ is thermal conductivity of water; $d_{\mathrm{i}}$ is inner diameter of tube.

Use the McQuistion correlation to calculate convective heat transfer coefficient $\left(\alpha_{\mathrm{o}}\right)$ of outer surface of fin tube:

$$
j_{N} / j_{4}=0.992\left[2.24 R e_{\mathrm{d}}^{-0.092}\left(\frac{N}{4}\right)^{-0.031}\right]^{0.607(N-4)}
$$

Where $j$ is surface heat transfer factor; $N$ is number of tube rows $(<4) ; R e_{\mathrm{d}}$ is Reynolds number of outer diameter of tube.

Parameters of outlet air state when surface air cooler is under dry or wet condition are calculated by the heat exchange efficiency coefficient method. Equivalent dry cooling condition method is adopted for wet condition [14], and then apparatus dew point $\left(t_{3}\right)$ can be got by the following formula:

$$
t_{3}=\frac{\left(\varepsilon_{2}-\varepsilon_{1}\right)\left(t_{\mathrm{g} 1}-t_{\mathrm{L} 1}\right) t_{\mathrm{s} 1}+\varepsilon_{1}\left(t_{\mathrm{s} 1}-t_{\mathrm{L} 1}\right) t_{\mathrm{w} 1}}{\left(\varepsilon_{2}-\varepsilon_{1}\right)\left(t_{\mathrm{g} 1}-t_{\mathrm{s} 1}\right)+\varepsilon_{2}\left(t_{\mathrm{s} 1}-t_{\mathrm{L} 1}\right)}
$$

If $t_{3}>t_{\mathrm{L} 1}$, surface air cooler is under dry condition, otherwise, under wet condition. When it is under dry condition, parameters of outlet air state calculated as follows:

$$
\begin{aligned}
& t_{\mathrm{g} 2}=t_{\mathrm{g} 1}-\varepsilon_{1}\left(t_{\mathrm{g} 1}-t_{\mathrm{w} 1}\right) \\
& t_{\mathrm{s} 2}=t_{\mathrm{L} 1}+\left(t_{\mathrm{g} 2}-t_{\mathrm{L} 1}\right)\left(t_{\mathrm{s} 1}-t_{\mathrm{L} 1}\right) /\left(t_{\mathrm{g} 1}-t_{\mathrm{L} 1}\right)
\end{aligned}
$$

When it is under wet condition, parameters of outlet air state calculated as follows:

$$
\begin{aligned}
& t_{\mathrm{g} 2}=t_{\mathrm{g} 1}-\varepsilon_{2}\left(t_{\mathrm{g} 1}-t_{3}\right) \\
& t_{\mathrm{s} 2}=t_{\mathrm{g} 2}-\left(1-\varepsilon_{2}\right)\left(t_{\mathrm{g} 1}-t_{\mathrm{s} 1}\right)
\end{aligned}
$$

In equations (5-9), $t_{\mathrm{L} 1}$ is dew point temperature of inlet air; $\varepsilon_{1}$ and $\varepsilon_{2}$ are the full heat exchange efficiency and general heat exchange efficiency; $t_{\mathrm{g} 1}$ and $t_{\mathrm{g} 2}$ are inlet/outlet air dry-bulb temperature; $t_{\mathrm{s} 1}$ and $t_{\mathrm{s} 2}$ are inlet/outlet air wet-bulb temperature.

\section{Simulated and experimental study on the thermal-moisture segmented handling system}

Construction of an experiment platform. In order to verify the accuracy of the performance simulation model of thermal-moisture segmented handling system and carry out experimental research, an experimental platform of the segmented handling air-conditioning system is build up, as shown in 
Fig. 2. The experimental platform includes high/low temperature water chillers, AHU and cooling water system. High/low temperature water chillers both use R22 refrigerant, electrical heater is set at chilled water inlet of evaporator to control the supply temperature of chilled water.

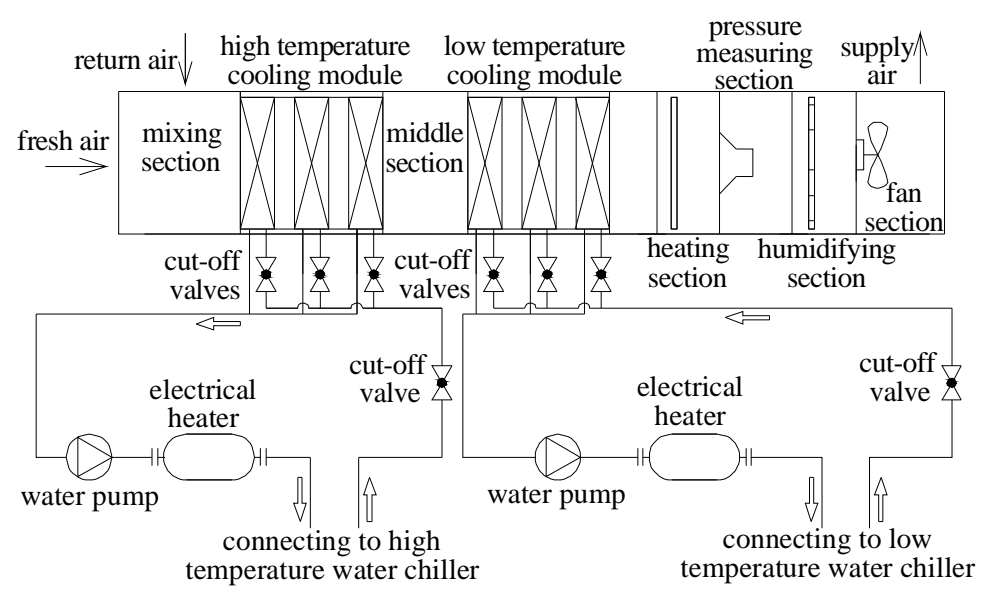

Fig.2 Experimental schematic of the thermal-moisture segmented handling system.

There are three surface air coolers in high/low temperature cooling module, having 1 row, 2 rows and 3 rows of fin tube respectively. The total row number in cooling module is set as constant 4 to ensure the total heat exchange area of surface air cooler unchanged during experiment by switching the cut-off valves of high/low temperature chilled water; and temperature measurement uses platinum resistance temperature sensor whose measuring range is $-200-500^{\circ} \mathrm{C}$ and accuracy is $\pm 0.15^{\circ} \mathrm{C}$; Water flow measurement uses turbine flowmeter whose measuring range is $0.6-6 \mathrm{~m}^{3} \mathrm{~h}^{-1}$ and accuracy is $1.0 \%$; Air flow measurement is achieved by measuring pressure difference before and after the nozzle in pressure measuring section, and the measurement of pressure difference uses differential pressure transmitter whose measuring range is $0-1000 \mathrm{~Pa}$ and accuracy is $\pm 0.15 \% \mathrm{FS}$.

Impact study of the row number ratios on performance of the system. Comparison of simulated and experimental study on performance of the segmented handling air-conditioning system on different row number ratios when the supply temperature of high temperature chilled water changes has been done based on the simulation model and experiment platform. During experiment and simulation, the supply temperature of low temperature chilled water is set as $7^{\circ} \mathrm{C}$, the high/low temperature chilled water flow are both $0.35 \mathrm{~kg} \mathrm{~s}^{-1}$; the dry-bulb temperature and relative humidity of mixed air out of the mixing section are $26^{\circ} \mathrm{C}, 50 \%$, air flow is $1560 \mathrm{~m}^{3} \mathrm{~h}^{-1}$; adjust compressor frequency of high temperature water chiller to ensure the supply temperature of high temperature chilled water change in the range of $7-19^{\circ} \mathrm{C}$; the row number ratio of high/low temperature surface air coolers is set up as $2: 2,1: 3,3: 1$ respectively.

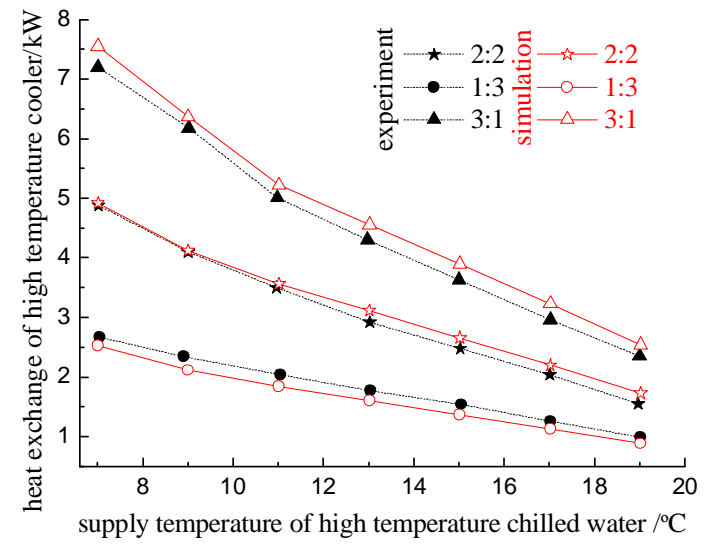

(a) heat exchange of high temperature cooling module

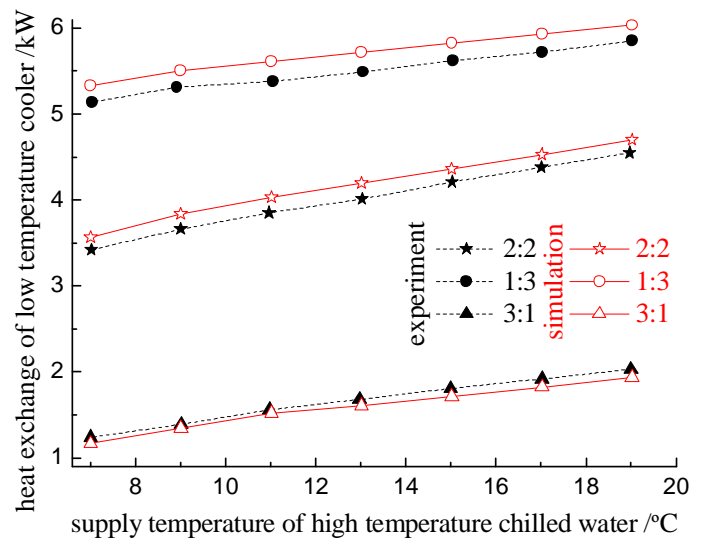

(b) heat exchange of low temperature cooling module 


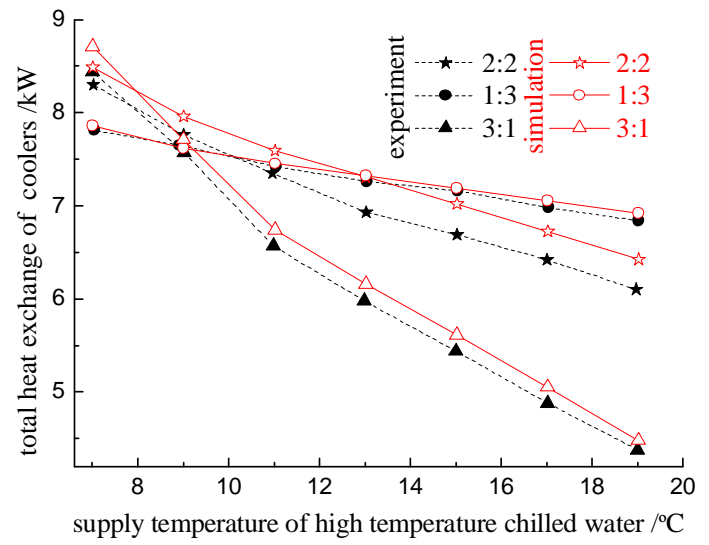

(c) total heat exchange of cooling module

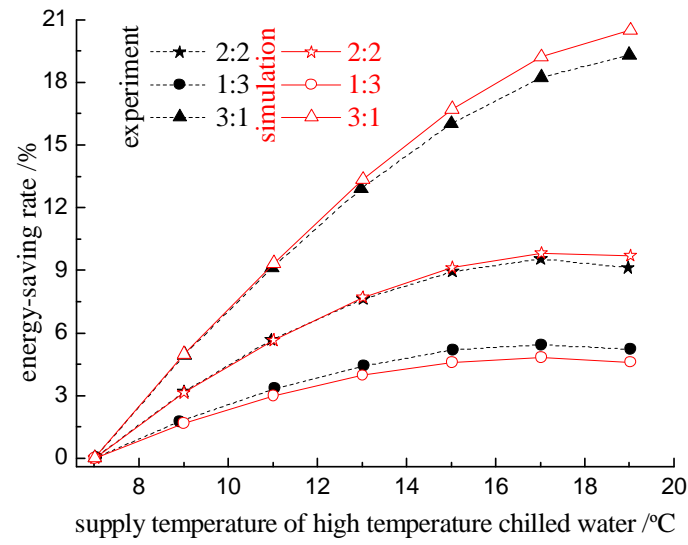

(d) energy-saving rate

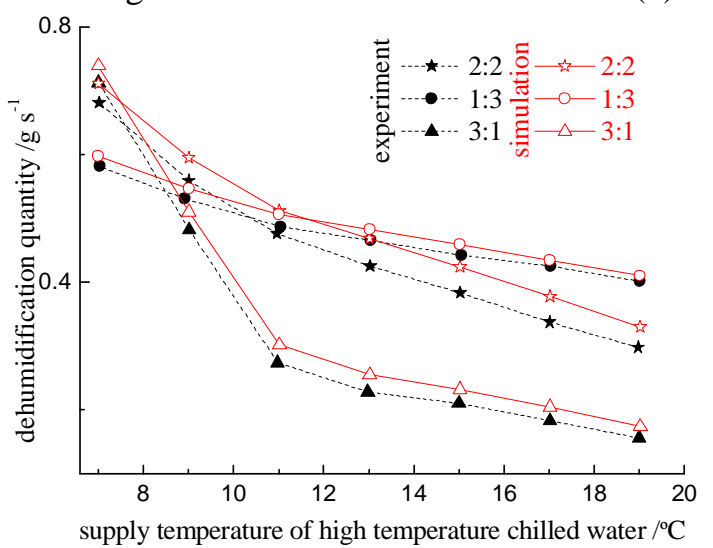

(e) dehumidification quantity

Fig.3 Comparison graphs of experimental and simulated results.

As showed in Fig. 3, with the increase of the supply temperature of high temperature chilled water, the results can be got when simulated values are compared with experimental ones: the maximum deviation of heat exchange in high temperature surface air cooler is within 11.3\%; the maximum deviation of heat exchange in low temperature surface air cooler is within $6.1 \%$; the maximum deviation of total heat exchange in high/low temperature surface air coolers is within 5.5\%; and the maximum deviation of energy-saving rate and dehumidification quantity are both within 11.9\%; the main reason leading to the deviation between simulation and experiment is that the simulation model ignores the heat loss caused by the heat exchange between the air-conditioning system and environment. The results of simulation and experiment show that this simulation model of thermal-moisture segmented handling system has the feature of high precision and meets the performance prediction demand of the system. During the supply temperature of high temperature chilled water rising from $7{ }^{\circ} \mathrm{C}$ to $19^{\circ} \mathrm{C}$, Fig. 3 (c) shows that the total heat exchange of high/low temperature surface air coolers on three different row number ratios all decrease, and the adjustable range on $3: 1>$ on $2: 2>$ on 1:3, which means the load regulation ability of the system on $3: 1$ is the best; Fig. 3 (d) shows that the energy-saving rate of the system on three different row number ratios increase first and then decrease, the increase range on $3: 1>$ on $2: 2>$ on 1:3, the energy-saving rate of the system on 3:1 reaches a maximum of $19.3 \%$ when the supply temperature of high temperature chilled water is $19^{\circ} \mathrm{C}$; And Fig. 3 (e) shows that the dehumidification quantity of the system on three different row number ratios all decrease, the dehumidification quantity on $3: 1$ reduces most, up to $78.1 \%$. It can be seen form Fig. 3(a), (c) and (e) that the heat exchange in high temperature surface air cooler, the total heat exchange and the dehumidification quantity are more likely to be affected by the change of the supply temperature of high temperature chilled water when the supply temperature of high temperature chilled water is at $7-11^{\circ} \mathrm{C}$, that is because the high temperature surface air cooler is in wet condition where is good for heat and mass transfer, so the supply temperature of high temperature chilled water is recommend $7-11^{\circ} \mathrm{C}$ to meet the requirements of the air latent heat load when the requirement of the dehumidification quantity is relatively high. 


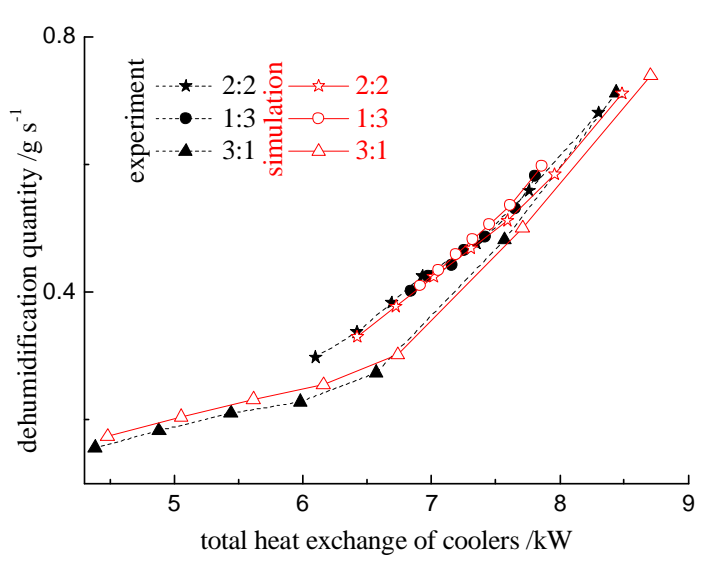

(a) dehumidification quantity

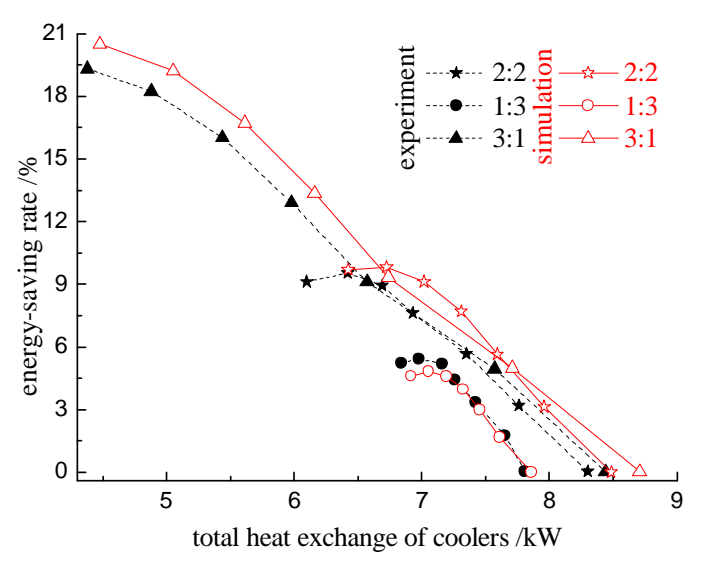

(d) energy-saving rate

Fig.4 curves of dehumidification quantity and energy-saving rate with total heat exchange.

In order to further reveal the variation of performance of the segmented handling air-conditioning system on three different row number ratios under part load, the relationship curves of dehumidification quantity and energy-saving rate with the total heat exchange in high/low temperature surface air coolers are made respectively, as shown in Fig. 4. With the decrease of the total heat, the dehumidification quantity of the system on three different row number ratios all decrease and the variation range on $3: 1>$ on $2: 2>$ on $1: 3$, moreover, dehumidification ability on $2: 2$ is equivalent to on $1: 3$ and is better than on 3:1, as can be seen from Fig. 4 (a); The energy-saving rate of the system on three different row number ratios increase first and then decrease, and the energy-saving rate on 2:2 is equivalent to on 3:1 when the total heat exchange(namely the part load is larger) is $6.6 \mathrm{~kW}$ or more, as can be seen from Fig. 4 (b).

\section{Conclusions}

1) The accuracy of the performance simulation model of thermal-moisture segmented handling system is verified by the experimental platform of the segmented handling air-conditioning system. According to the results of simulation and experiment, the relative errors of main performance parameters such as total heat exchange, energy-saving rate and dehumidification quantity between simulation and experiment are within $12 \%$, which shows that the simulation model of the system has a higher precision, and meets the performance prediction demand.

2) The adjustable range of total heat exchange and dehumidification quantity of the system caused by the supply temperature of high temperature chilled water increasing from 7 to $19^{\circ} \mathrm{C}$ on $3: 1$ is bigger than on 2:2 and on 1:3, and the energy-saving rate of the system on 3:1 is the most, up to $19.3 \%$.

3) The dehumidification ability of system on $2: 2$ is equivalent to on $1: 3$ and is better than on $3: 1$ when the total heat exchange of the system on three different row number ratios is all the same; The energy-saving rate increase first and then decrease with the decrease of the total heat; The energy-saving rate of system on 2:2 is equivalent to on 3:1 and the dehumidification ability of system on $2: 2$ is better than $3: 1$ when the part load is $6.6 \mathrm{~kW}$ or more, and the system on $3: 1$ has a higher energy-saving rate when the part load is less than $6.6 \mathrm{~kW}$.

\section{Acknowledgements}

This work was financially supported by the "12th Five-Year" National Science and Technology Support Plan Project (2011BAJ03B10), the National Natural Science Foundation of China (51106023) and the Key Project of Natural Science Foundation of Jiangsu Province (BK2010029).

\section{References}

[1] Saidur R, Hasanuzzaman M, Mahlia T M I, et al. Chillers energy consumption, energy savings and emission analysis in an institutional buildings[J]. Energy, 2011, 36(8): 5233-5238. 
[2] Lee T S, Liao K Y, Lu W C. Evaluation of the suitability of empirically-based models for predicting energy performance of centrifugal water chillers with variable chilled water flow[J]. Applied Energy, 2012, 93: 583-595.

[3] Beghi A, Cecchinato L, Cosi G, et al. A PSO-based algorithm for optimal multiple chiller systems operation[J]. Applied Thermal Engineering, 2012, 32: 31-40.

[4] Cecchinato L. Part load efficiency of packaged air-cooled water chillers with inverter driven scroll compressors[J]. Energy Conversion and Management, 2010, 51(7): 1500-1509.

[5] LIU Xuefeng, LIU Jinping, CHEN Xinglong, et al. Static Stability Analysis of Air-Conditioning Chilled Water System for Variable Differential Pressure Control Considering Bypass Loop Regulation Characteristics[J]. Journal of Shanghai Jiao Tong University, 2014, 6: 772-777. (in Chinese)

[6] Yu F W, Chan K T. Economic benefits of optimal control for water-cooled chiller systems serving hotels in a subtropical climate[J]. Energy and Buildings, 2010, 42(2): 203-209.

[7] Navale R L, Nelson R M. Use of genetic algorithms and evolutionary strategies to develop an adaptive fuzzy logic controller for a cooling coil-Comparison of the AFLC with a standard PID controller[J]. Energy and Buildings, 2012, 45: 169-180.

[8] Hou Z, Qu M, Wang Z. Effectiveness Model of Cooling Coil Unit Based on Parameters Identification[C]//ASME 2014 8th International Conference on Energy Sustainability collocated with the ASME 2014 12th International Conference on Fuel Cell Science, Engineering and Technology. American Society of Mechanical Engineers, 2014: V002T12A007-V002T12A011.

[9] MEI Kui, LIANG Caihua, ZHANG Xiaosong. Influence of variable-volume on performance of cooling coil[J]. Journal of Chemical Industry and Engineering, 2008, 59(S2): 109-113. (in Chinese)

[10] Lee C K. A simplified explicit model for determining the performance of a chilled water cooling coil[J]. International Journal of Refrigeration, 2014, 43: 167-175.

[11] Liang Caihua, Zhang Xiaosong, Jiang Yunyu, et al. Novel air handling method and its energy-saving potential in air-condition system[J]. Journal of Southeast University(Natural Science Edition), 2009, 39(5): 973-977. (in Chinese)

[12] Zhao K, Liu X H, Zhang T, et al. Performance of temperature and humidity independent control air-conditioning system in an office building[J]. Energy and Buildings, 2011, 43(8): 1895-1903.

[13] Liang Caihua, Zhang Xiaosong, Xu Guoying. Simulative and Experimental Studies on the Effect of Superheat Degree on the Refrigeration System Performance[J]. Fluid Machinery, 2005, 33(9): 43-47. (in Chinese)

[14] Wang J S, Cheng B Y, Miao X P, etal.Simpl ified thermodynamic calculation of surface-type air coolers for general conditions[J]. HV\&AC. 1997, 27(A10): 54-56. (in Chinese) 